\title{
Dinophyceae can use exudates as weapons against the parasite Amoebophrya sp. (Syndiniales)
}

\author{
Marc Long $\mathbb{D}^{1 凶}{ }^{凶}$, Dominique Marie ${ }^{2}$, Jeremy Szymczak ${ }^{2}$, Jordan Toullec ${ }^{1}$, Estelle Bigeard ${ }^{2}$, Marc Sourisseau ${ }^{1}$, Mickael Le Gac ${ }^{1}$, \\ Laure Guillou ${ }^{2}$ and Cécile Jauzein ${ }^{1}$
}

(c) The Author(s) 2021, corrected publication 2022

Parasites in the genus Amoebophrya sp. infest dinoflagellate hosts in marine ecosystems and can be determining factors in the demise of blooms, including toxic red tides. These parasitic protists, however, rarely cause the total collapse of Dinophyceae blooms. Experimental addition of parasite-resistant Dinophyceae (Alexandrium minutum or Scrippsiella donghaienis) or exudates into a well-established host-parasite coculture (Scrippsiella acuminata-Amoebophrya sp.) mitigated parasite success and increased the survival of the sensitive host. This effect was mediated by waterborne molecules without the need for a physical contact. The strength of the parasite defenses varied between dinoflagellate species, and strains of $A$. minutum and was enhanced with increasing resistant host cell concentrations. The addition of resistant strains or exudates never prevented the parasite transmission entirely. Survival time of Amoebophrya sp. free-living stages (dinospores) decreased in presence of $A$. minutum but not of $S$. donghaienis. Parasite progeny drastically decreased with both species. Integrity of the dinospore membrane was altered by $A$. minutum, providing a first indication on the mode of action of anti-parasitic molecules. These results demonstrate that extracellular defenses can be an effective strategy against parasites that protects not only the resistant cells producing them, but also the surrounding community.

ISME Communications; (2021)1:34; https://doi.org/10.1038/s43705-021-00035-x

\section{INTRODUCTION}

Parasites, thought to account for half of species richness in some ecosystems, could constitute the unseen majority of species extinctions [1]. The majority of parasites have essential ecological roles by contributing to the balance of ecosystems, limiting invasions and emergence of infectious diseases and contributing to biomass transfer between trophic levels [2-4]. In marine ecosystems, parasites have a predominant role in the planktonic protist interactome, as inferred by sequence-based correlation networks [5], accounting for up to $18 \%$ of interactions [6]. Parasites are important contributors to phytoplankton mortality and can sometimes induce the demise of microalgal blooms [7-9].

Amongst marine parasites, the Syndiniales Amoebophryidae (also called marine Alveolate group II, or MALVII) is a widely distributed family $[10,11]$. This group is ubiquitous in marine waters, including ultra-oligotrophic environments [12] and has been associated with the demise of toxic microalgal species $[8,13-16]$ in enriched coastal environments. The Amoebophryidae life cycle is characterized by a free-swimming stage (dinospores, referred to as zoospores) followed by two, successive, intracellular stages (trophont then sporont) that eventually kill the host and release hundreds of dinospores. Dinospores are flagellated unicellular forms that survive a few hours to a few days in culture [17].

Amoebophrya spp. are specialist parasites that require a compatible host to complete their life cycle. The overall consistency in the host spectrum observed within different strains of the same species suggests a genetic determinism underlying host specialization [18]. Many factors can influence the parasitic population dynamic such as physical (e.g., temperature, water column depth, physical mixing) and chemical (e.g., nutrients) parameters [19]. Optimal abiotic conditions for parasitic infection do not always induce the collapse of targeted dinoflagellate blooms, implicating complex biotic interactions as fundamental to the parasite success [19]. Modeling approaches also indicate that parasitic control of dinoflagellate blooms strongly depends upon the plankton community structure (e.g., cell densities, grazing of free-living stages of parasite stages, competition between cells) [20]. Coexistence between resistant and sensitive hosts could affect parasite propagation through different mechanisms, including dilution effects $[20,21]$ or through cell signaling as suggested in viral infections $[9,22]$.

Mechanisms of dinoflagellate host resistance against parasites are poorly known. Different strategies have been described to date, including the production of resting stages [23, 24], the production of intracellular anti-parasitic metabolites [25-29], sometimes released into exudates [29]. The release of antiparasitic compounds (APC) is a strategy that can be classified within the more general term of allelopathy. The term "allelochemical" refers to any secondary metabolite exuded by a microalga that affects the growth of another co-occurring protist [30]. Whether and how the release of APC can influence the dynamics of parasites remains an open question.

${ }^{1}$ IFREMER, Centre de Brest, DYNECO Pelagos, F-29280, Plouzané, France. ${ }^{2}$ UMR 7144 Sorbonne Université \& Centre National pour la Recherche Scientifique, «Adaptation and Diversity in Marine Environment», Team «Ecology of Marine Plankton, ECOMAP», Station Biologique de Roscoff, 29680, Roscoff, France. ${ }^{凶}$ email: marc.florian.long@gmail.com

Received: 25 February 2021 Revised: 21 May 2021 Accepted: 2 June 2021

Published online: 12 July 2021 
This study investigated whether or not co-occurring Dinophyceae, resistant to Amoebophrya sp., can affect the dynamics of infection of a sensitive Dinophyceae host. The well-established parasitic couple Amoebophrya sp. (A25)—Scrippsiella acuminata (ST147) [31] was studied in the presence and absence of resistant dinoflagellate host cells or exudates. Two dinoflagellate species, Scrippsiella donghaienis and Alexandrium minutum, were selected for several reasons: (a) they can form recurrent dense blooms [32-34] and are potential competitors of S. acuminata, (b) they cooccur with $S$. acuminata and Amoebophrya sp. in the same estuaries $[10,18]$, (c) they are resistant to Amoebophrya sp. (A25) [18] and (d) A. minutum cells are producers of allelochemicals with lytic activity against competing protists $[35,36]$. The production of allelochemicals by $S$. donghaienis has not been reported. A series of different experimental set-ups were performed to further characterize the interactions. First, we tested the hypothesis that the presence of resistant cells could inhibit the propagation of the infection in cocultures, allowing cell-cell and chemical interactions. To evaluate potential effects of chemical cues upon the interaction, a second set of experiments was performed to study the possible effects of exudates upon the viability of the dinospores and the infection cycle. A third experiment tested the hypothesis that a loss of dinospore viability was linked to A. minutum lytic potency.

\section{MATERIALS AND METHODS \\ Biological material}

Origin of strains and culture conditions. The five hosts and the parasitic strains originated from coastal marine waters of the NE Atlantic Ocean (Table S1). All strains were non-axenic but were cultured under sterile conditions to avoid additional contamination. The parasite Amoebophrya sp. strain A25 (RCC4383) was maintained routinely using the sensitive S. acuminata clade STR1 (ST147; RCC1627; previously named S. trochoidea) as compatible host. Resistant dinoflagellates used in this study were A. minutum (strains CCMI1002, Am176 also named RCC749, DA1257) and S. donghaienis (strain Sc39 or RCC4714 sampled during an A. minutum bloom). Infected and uninfected host cultures were maintained in a medium prepared with seawater (27 of salinity) from the Penzé estuary (France), stored in the dark for several months before being used, filtered to $0.22 \mu \mathrm{m}$, autoclaved, and enriched with modified $F / 2$ nutrients (Guillard's Marine Water Enrichment Solution, Sigma) and 5\% (v/v) soil extract [37]. Cultures used for Experiment 3 were prepared using a different medium ( $\mathrm{K}$ medium [38], seawater from Argenton, France at 35 of salinity) after acclimation of strains. In both cases, a final filtration $(0.22 \mu \mathrm{m}$ pore size filter) under sterile conditions, was done after addition of nutritive solutions. Stock cultures and experiments were incubated under continuous light $\left(90-140 \mu \mathrm{E} \mathrm{m}^{-2} \mathrm{~s}^{-1}\right.$, light bulb Sylvania Aquastar F18W/ 174 or EASY LED universal light $438 \mathrm{~mm}$ ) at $21 \pm 1-2^{\circ} \mathrm{C}$. All experiments were performed with plastic flasks (CytoOne vented flasks in polystyrene).

Uninfected hosts were kept in exponential growth phase by diluting 5 volumes of stock culture into 8 volumes of fresh medium every 3-4 days. Infections were propagated by diluting 1:5 (vol:vol) of the infected culture into healthy hosts S. acuminata (ST147) every 3-4 days.

Synchronization and collection of Amoebophrya dinospores. Density and infectivity of dinospores decrease rapidly after release (Table S2); therefore the use of freshly released dinospores helps to maximize infections in the flask. To produce freshly released dinospores, cultures of parasites were synchronized (unless specified) following the protocol [39]. During synchronization, infections were initiated with 3-day-old cultures of Amoebophrya from which dinospores were collected after a gentle separation from the remaining host cells (S. acuminata ST147) using gravity filtration through nylon filter $(5 \mu \mathrm{m}$, Whatman). These dinospores were incubated with the exponentially growing host S. acuminata (strain ST147) using a 1:2 parasite:host (vol:vol) ratio to encourage infection of host cells. After $24 \mathrm{~h}$ of incubation, infected hosts were collected by filtration on a $5 \mu \mathrm{m}$ nylon filter then resuspended in an equal volume of new medium, to remove remaining free-living dinospores. Three days later, freshly liberated dinospores of the same age (i.e., synchronized) were separated from remaining host cells by filtration as described before. In prior experiments, no effect of dilutions on dinospore survival over $24 \mathrm{~h}$ was observed using fresh culture medium, exudates from the healthy host ST147, or exudates from ST147xA25 infected culture (Table S2). Hereafter, filtrates from ST147 cultures in exponential growth were used to adjust densities by dilution.

Preparation of microalgal filtrates. Exudates from exponentially growing microalgal strains were collected by filtration $(0.2 \mu \mathrm{m}$, acetate cellulose membrane, Minisart) using gentle pressure through a syringe. In the present study, dilution of exudates was expressed as equivalent to the microalgal density (corresponding to the theoretical concentration of cells that would have been reached by the initial culture after a similar dilution). Diluted exudates were used immediately for experiments.

\section{Cell counting methods}

Flow-cytometry (FCM): cell count and membrane permeability. Densities and individual cell variables (e.g., forward scatter, size scatter, fluorescence signals) were measured using a flow cytometer equipped with $488 \mathrm{~nm}$ and $405 \mathrm{~nm}$ lasers. A FACSAria flow cytometer (Becton Dickinson) was used in experiments 1 and 2; a Novocyte Advanteon (ACEA Biosciences) was used in experiment 3. Dinophyceae were discriminated from other particles by red chlorophyll autofluorescence. Free-living (dinospores) and late stages of infection of Amoebophrya spp. emit a bright green autofluorescence when excited under blue-violet light [23, 40, 41], a proxy of the parasite survival [17]. This natural autofluorescence was used to estimate the density of viable dinospores by FCM using the $405 \mathrm{~nm}$ laser.

Intact cell membranes are impermeable to the SytoxGreen (SYTOX Green nucleic acid stain, Invitrogen), but DNA in cells with altered (i.e., permeable) membranes is stained, emitting a bright green fluorescence. Samples were incubated with SytoxGreen (final concentration of $0.05 \mu \mathrm{M}$ ) for $20 \mathrm{~min}$ in the dark before measurement.

Prevalence of infections (CARD-FISH). CARD-FISH samples were fixed with paraformaldehyde ( $1 \%$ final concentration) for $1 \mathrm{~h}\left(4^{\circ} \mathrm{C}\right.$ in the dark) before filtration on a $0.8 \mu \mathrm{m}$, polycarbonate filter with a vacuum pump $(<200 \mathrm{~mm}$ $\mathrm{Hg}$ ). Filters were then dehydrated using successive $50 \%, 80 \%$, and $100 \%$ ethanol solutions, dried and stored in the dark at $-20^{\circ} \mathrm{C}$. FISH staining was then performed according to [8]. The prevalence was estimated from microscope observations with an Olympus BX-51 epifluorescence microscope (Olympus Optical) equipped with a mercury light source, a Wide Blue filter set (Chroma Technology, VT, USA) and fluorescence filter sets for PI (excitation: $536 \mathrm{~nm}$; emission: $617 \mathrm{~nm}$ ) and FITC (excitation: $495 \mathrm{~nm}$; emission: $520 \mathrm{~nm}$ ).

Prevalence was determined by averaging infection counts on a minimum of 80 cells per replicate. Prevalence was characterized in: noninfected host cells, early stage (one or more dinospores of Amoebophrya $\mathrm{sp}$. in the cytoplasm), and advanced stages (intermediate and beehive stages) as described in [42]. The progeny count (i.e., the number of dinospores per infected host) was estimated by dividing the maximal concentration of dinospores by the concentration of infected hosts in advanced stages.

\section{Experimental set-ups}

Experiment 1: cocultures. The dynamic of infection in cocultures was compared when mixing the parasite (Amoebophrya sp. A25) with a sensitive host (S. acuminata ST147) and a resistant host (A. minutum CCMI1002 or S. donghaienis SC39). Mixtures were prepared in triplicates, using a cell ratio of 1:1:1 (parasite:sensitive host:resistant host), with initial concentrations of 4000 cells $\mathrm{mL}^{-1}$ for each strain (Fig. 1a). Controls consisted of flasks containing: (i) only the compatible host ST147 at 4000 cells $\mathrm{mL}^{-1}$ or (ii) the host (ST147) at 4000 cells $\mathrm{mL}^{-1}$ and parasite $\mathrm{A} 25$ at a ratio of 1:1. An additional control consisted of mixing the host ST147 and one of the resistant hosts (CCMI1002 or Sc39) in parallel, replacing the parasite with $0.2 \mu \mathrm{m}$ filtrate from the host culture. All cultures and controls were started simultaneously, using the same inoculum cultures. Cell densities were quantified once or twice per day. At the end of the experiment, samples were fixed with non-acidic Lugol's solution ( $1 \%$ final concentration) for microscopic counts and differentiation between S. accuminata and $A$. minutum cells.

Experiments 2 and 3: evaluation of the effects of Dinophyceae filtrates upon Amoebophrya. Filtrates of microalgal cultures were used to analyze the effects of Dinophyceae exudates (from either A. minutum or S. donghaienis) 
(a)

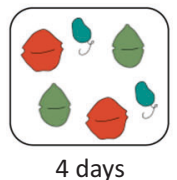

Conditions:

1 resistant host (CCMI1002)

1 ratio (1:1:1)
Set-up 1: Cocultures

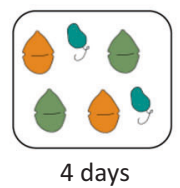

Conditions:

1 resistant host (Sc39)

1 ratio (1:1:1)

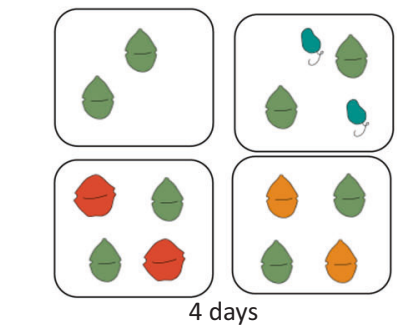

Conditions for the controls:

3 ratios (0:1:0), (0:1:1), (1:1:0) (b)

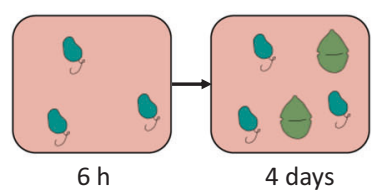

Conditions:

3 resistant hosts

(CCMI1002, AM89BM or DA1257)

1 ratio (5:1)

\section{Set-up 2: Chemical interactions}

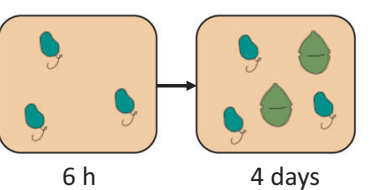

Conditions:

1 resistant host (Sc39)

3 ratios $(5: 1,1: 1,0,5: 1)$

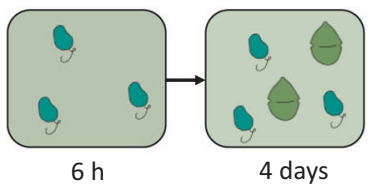

Conditions for the controls: 1 sensitive host (ST147) Control ratios $(5: 1,1: 1,0,5: 1)$

\section{(c) Set-up 3: Integrity of membranes \\ Legend \\ + SytoxGreen

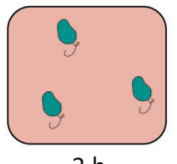 \\ $2 \mathrm{~h}$ \\ Condition: 1 resistant host (CCMI1002) \\ + SytoxGreen

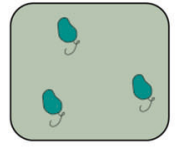 \\ Resistant host: \\ Alexandrium minutum (Am) \\ Resistant host: \\ Scrippsiella donghaienis (Sd) $\square$ Sd filtrate \\ Sensitive host: \\ Scrippsiella acuminata (Sa) $\square$ Sa filtrate \\ Parasite: \\ Amoebophrya sp. (P) \\ Coculture}

Fig. 1 Graphical protocol for the study of chemical defenses against Amoebophrya sp. a Experimental setup for the coculture experiments. This experiment was conducted over 4 days. The ratios are indicated as (parasite:compatible host:resistant host). $\mathbf{b}$ Experimental setup for the study of chemical interactions through exudation. This experiment was conducted in two sub-parts, a first pre-exposure to the filtrates over 6 $\mathrm{h}$ and an infection of compatible hosts over 4 days. The ratios are indicated as (parasite:compatible host). c Experimental protocol for the study of membrane integrity. The exposure to the filtrate was conducted over $2 \mathrm{~h}$ and compared to dinospores in their own media.

upon Amoebophrya. Experiment 2 was organized into two parts (Fig. 1b): the first to estimate the effect of Dinophycae exudates upon the abundance of autofluorescent dinospores, and the second to analyze the potential for infection and production of a second generation of dinospores after $6 \mathrm{~h}$ of contact with the filtrates. The $6 \mathrm{~h}$ pre-exposure was chosen to have a stable density of dinospore (Fig. S1) at the moment of the infection.

First, dinospores from Amoebophrya sp. (A25) were exposed to dilutions of dinoflagellate filtrates (equivalent to 1,000 and 5,000 and 10,000 cells $\mathrm{mL}^{-1}$ ) collected from three strains of $A$. minutum (DA1257, AM176, CCMI1002) and for one strain of S. donghaienis (SC39). Counts of autofluorescent dinospores were monitored by FCM. The mortality rate $\left(\mathrm{h}^{-1}\right)$ of autofluorescent dinospores was calculated over the first 3 h according to Eq. 1, where $N_{1}$ and $N_{2}$ are the respective densities of autofluorescent dinospores before and after $3 \mathrm{~h}$ of exposure to the filtrates. Controls consisted of dinospores incubated with exudates from the host ST147. Incubations for controls and using the highest filtrate concentrations $\left(10,000\right.$ cells $\left.\mathrm{mL}^{-1}\right)$ were performed in triplicates; whereas only one replicate was performed for intermediate concentrations.

Mortality rate $=\frac{\ln \left(N_{1} / N_{2}\right)}{3}$

Then, dinospores previously exposed to the maximal concentration of exudates and in the control conditions after $6 \mathrm{~h}$ of incubation were used for the second part of the experiment (Fig. 1b). Exposeddinospores were mixed with the host strain ST147 at a theoretical cell ratio of 5:1 (dinospore:host) for dinospores exposed to $A$. minutum filtrates, and at three different ratios $(1: 2,1: 1$, and 5:1) for dinospores exposed to $S$. donghaienis filtrate. These ratios were calculated according to the initial dinospore density before exposure to filtrates and did not consider the possible differential losses related to filtrates. The production of dinospores was monitored twice per day during 5 days by FCM, and prevalence was analyzed after $47 \mathrm{~h}$ of incubation by CARD-FISH in the controls and with the CMMI1002 and Sc39 filtrate treatments. 

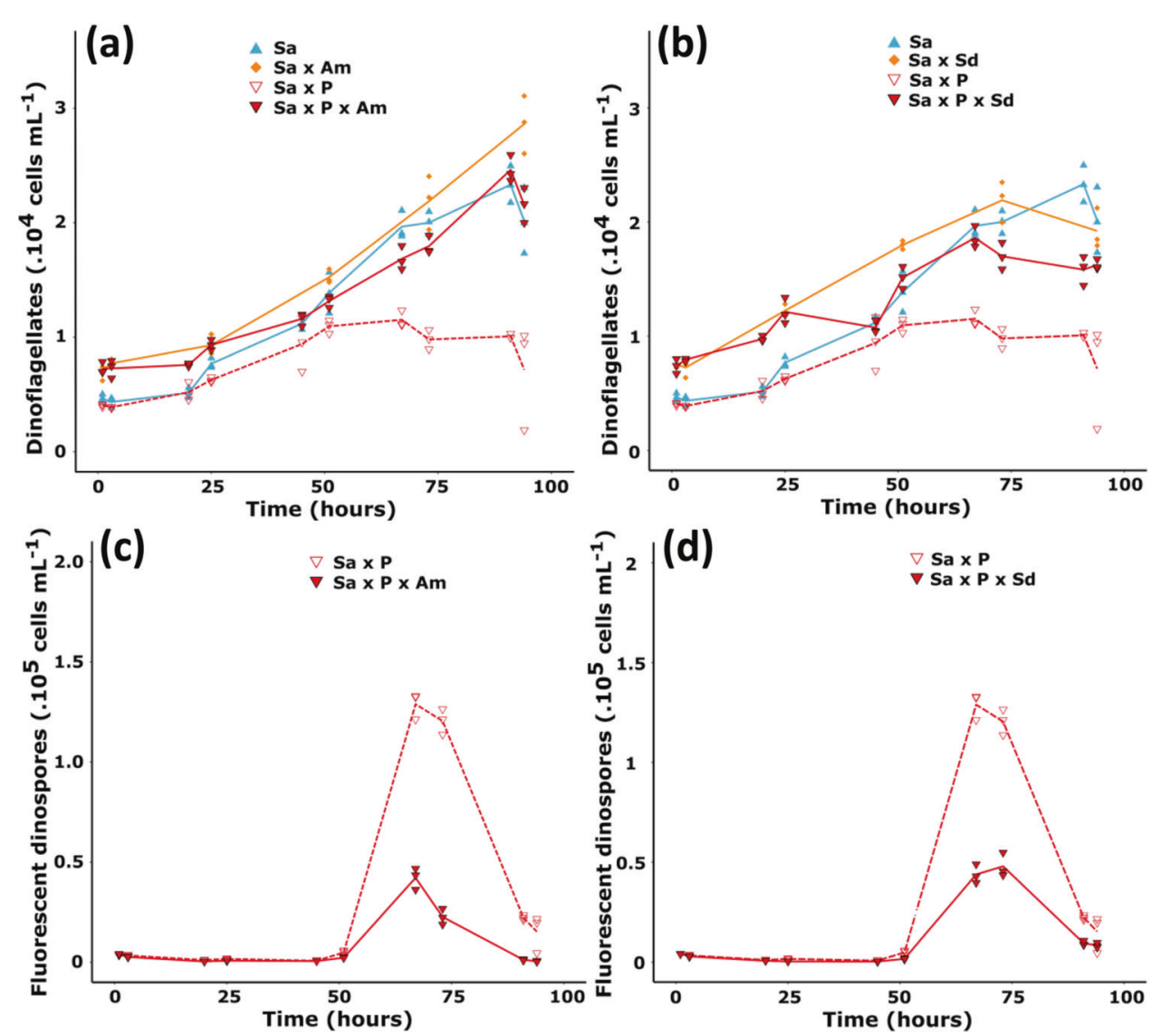

Fig. 2 Effect of cocultures on the dynamic of infection. Cocultures of the parasite Amoebophrya sp. (P; strain A25) with its compatible host $S$. acuminata (Sa; strain ST147) and a secondary resistant host, either a, b A. minutum (Am; strain CCMI1002) or c, d S. donghaienis (Sd; strain Sc39). Densities of dinoflagellates (S. accuminata with S. donghaienis or A. minutum) are shown in (a) and (c). Densities of autofluorescent dinospores are shown in (b) and (d). The same controls ( $\mathrm{Sa}$ and $\mathrm{Sa} \times \mathrm{P}$ ) are shown for both species as experiments were performed at the meantime. Lines represent the mean cell densities while the symbols represent the values of each replicate $(N=3)$.

Experiment 3 was performed to monitor the concentrations of autofluorescent dinospores and their membrane integrity over time when mixed with $A$. minutum exudates compared to the control (Fig. 1c). Dinospores from 3-day-old parasite cultures (non-synchronized) of Amoebophrya sp. A25 were harvested by filtration $(5 \mu \mathrm{m}$, cellulose acetate, Minisart). Dinospores were exposed in triplicate to $A$. minutum CCMI1002 filtrate at a final concentration of 5,000 theoretical cells $\mathrm{mL}^{-1}$ in six-well plates (CytoOne, polystyrene). In the control, dinospores were diluted in triplicate with S. acuminata (ST147) filtrate. The dinospore concentrations and the permeability of their membranes were estimated after 20,40,60, and 120 min of incubation with the filtrate.

\section{Statistics}

Statistical analyses were performed using $\mathrm{R}$ software [43]. Significant differences in the dependent variables (e.g., concentrations of microalgae and dinospores, prevalence) were assessed with a test of student or oneway ANOVA followed by a post-hoc Tukey HSD, when data met homoscedasticity with a Bartlett test and normality with a Shapiro-Wilk test. When homoscedasticity or normality could not be met, a nonparametric Krukal-Wallis test followed by a post-hoc Conover with a bonferroni adjustment was applied. All tests were performed with a significance level of $p$ value $=0.05$. Results are expressed as mean \pm standard deviation.

\section{RESULTS}

Infections were mitigated by the presence of a resistant host Experiment 1 tested whether or not the co-presence of a resistant host (A. minutum or $S$. donghaienis) could modify Amoebophrya infection dynamics with a sensitive host (S. acuminata). In controls and when using fixed experimental culture conditions, a complete infection cycle lasted at least $51 \mathrm{~h}$ and ended with the sudden released of freshly produced dinospores. During that period, infected host cells do not divide [13], which explain the lower net growth rates recorded $25 \mathrm{~h}$ after the parasite inoculation compared to the controls (Fig. 2a, b). Addition of a resistant host (CCMI1002 or Sc39) did not modify the duration of the parasite development, but always resulted in a significant decrease (> $60 \%$ ) of dinospore production (Fig. 2c, d). This observation could result from a deleterious effect on the sensitive host, a direct effect upon dinospore survival/infectivity, or both. Cocultivation with $A$. minutum also has a cost for S. acuminata. At the end of the experiment, densities of $S$. acuminata in the coculture without parasite were of $6,900 \pm 1,400$ cells $\mathrm{mL}^{-1}$ while it reached $20,000 \pm 3,000$ cells $\mathrm{mL}^{-1}$ in the control.

\section{Exudates from $A$. minutum decreased the density of viable dinospores}

Autofluorescence of dinospores can be used as a proxy for their viability [17]. In controls, $25 \%$ of fluorescent dinospores were lost after $6 \mathrm{~h}$, leading to a natural mortality rate of $0.07 \pm 0.01 \mathrm{~h}^{-1}$ in tested cultures conditions (Fig. 3). Experiment 2 tested whether or not resistant dinoflagellate exudates affected mortality rate. If exposure to $A$. minutum filtrates significantly increased mortality ( $p$ values $<0.02$ ) compared to the control (Fig. 3a), no significant effect using S. donghaienis (Sc39) filtrate was observed (Fig. 3b). For A. minutum, this deleterious effect was strain-dependent: the mortality rate of dinospores exposed to strain DA1257 (0.11 \pm 
(a)

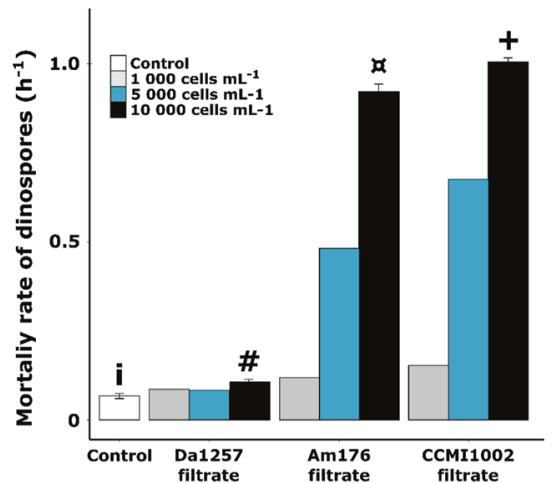

(b)

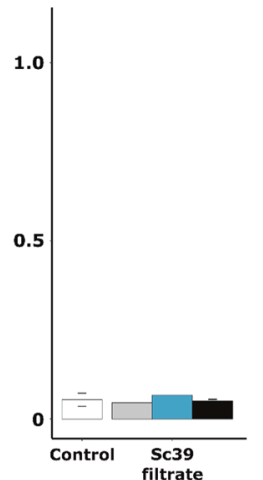

Fig. 3 Maximal mortality rate of autofluorescent A25 dinospores in the different conditions. Dinospores were exposed to a $A$. minutum and $\mathbf{b} S$. donghaienis filtrates during two separate sets of experiment. Results are expressed as the value or the mean \pm standard deviation when replicates were performed $(N=3)$. Significant differences $(p$ value $<0.05)$ in the mortality rates are indicated by different symbols. The complete dataset, with all sampling points (after 1, 3 and $6 \mathrm{~h}$ ) is provided in Supporting Information Fig. S1.

$\left.0.01 \mathrm{~h}^{-1}\right)$ was much lower than those measured for AM176 $(0.92 \pm$ $\left.0.02 \mathrm{~h}^{-1}\right)$ or CCMI1002 $\left(1.00 \pm 0.01 \mathrm{~h}^{-1}\right)$. This resulted in losses of $32 \pm 1 \%, 96.1 \pm 0.2 \%$, and $97.2 \pm 0.4 \%$, respectively, of the initial density of autofluorescent dinospores after $6 \mathrm{~h}$ of exposure.

\section{Exudates from A. minutum decreased Amoebophrya sp. infectivity}

To test whether or not the loss of fluorescence (Experiment 2) was linked to a loss of infectivity, dinospores that were challenged for $6 \mathrm{~h}$ with exposure to exudates from three strains of $A$. minutum were then mixed with healthy host cultures. Cell densities were fixed for all treatments before the addition of exudates. However, because of the difference in mortality rates, the starting concentration of autofluorescent dinospores and the dinospores: host ratios differed over treatments: $41,000 \pm 1,400$ dinospores $\mathrm{mL}^{-1}$ in the control (ratio 4:1), and 36,000 $\pm 800,2,100 \pm 100$, and $1,500 \pm 200$ dinospores $\mathrm{mL}^{-1}$ with exudates of DA1257 (ratio 4:1), Am176 (ratio 1:5), and CCMI1002 (ratio 1:7), respectively. The ability of the remaining autofluorescent dinospores to infect the host, even at low and unfavorable ratios, then was explored.

The growth of the compatible host (S. acuminata ST147) was suppressed by the dinospores from the control or previously exposed to DA1257 filtrate (Fig. 4a). This suppression of the host growth in the control was linked to the high prevalence $(61 \pm 6 \%$ in the control; Table 1) of Amoebophrya sp. in host cells. In comparison, the compatible host in contact with dinospores previously exposed to AM176 or CCMI1002 filtrates remained able to grow during the first $42 \mathrm{~h}$ of incubation (Fig. $4 \mathrm{a}$ ) as the prevalence was lower (approximately a 35\% in the CCMI1002 treatment; Table 1). Between 42 and $80 \mathrm{~h}$, a collapse of the host population was observed in all conditions (Fig. 4a). The degree of the decline in host population was likely related to the prevalence of cells at advanced stages of infection (Table 1). With the CCMI1002 treatment, $30 \pm 4 \%$ of host cell losses were estimated (Fig. 4a) against $75 \pm 2 \%$ of host cell losses in the control.

Novel infections and dinospores releases were observed in all treatments (Fig. 4b). Filtrates of $A$. minutum did not seem to affect the intracellular stage as new progeny were released after $48 \mathrm{~h}$, and the duration of infection was similar over treatments. Progeny (dinospore production per infected host) was 100 times lower with CCMI1002 than in the control (Table 1). As a result of lower prevalence and lower progeny, the maximal dinospore concentration was drastically lower in the CCMI1002 and AM176 treatment (Fig. $4 b^{\prime}$ ) as compared to the control or DA1257 filtrate treatments ( $p$ values $<10^{-7}$ ).

The same experiment was conducted with Sc39, results from the $1: 1$ ratio are shown in Figs. $4 c, d$, results from cell ratios of $1: 2$ and 5:1 are presented in Fig. S2. In contrast to A. minutum filtrates, infections started with the same density of autofluorescent dinospores in the controls and in Sc39 treatments, as no effect was observed upon the autofluorescence of dinospores. Filtrates of $S$. donghaienis did not seem to affect the intracellular stage, as novel infections were observed and the duration of infection was similar to control conditions. Release of new progeny started between 48 and $50 \mathrm{~h}$ (Fig. 4d). The previous treatment of dinospores with Sc39 filtrate did not significantly affect the prevalence of Amoebophrya sp. (Table 1) nor affect the growth rate of the host during the first $48 \mathrm{~h}$ (Fig. $4 \mathrm{c}$ ). With or without the previous treatment with $S$. donghaienis filtrate, a sharp decline in host population, concomitant with release of new progeny, was observed after $48 \mathrm{~h}$. Overall there was no statistical difference in the percentage of lysed host cells between the treatments ST147 $(37 \pm 3 \%)$, and Sc39 (38 $\pm 4 \%)$. The main effect of pre-exposure of dinospores to Sc39 filtrate was observed in the new generation of dinospores: the treatment significantly decreased by $22 \%$ the maximum concentration of the new generation of dinospores (Fig. 4d and Supporting Information Fig. S2). This decrease did not seem to be linked to a lower prevalence but was more likely related to a lower number of progeny per infected host, even though the threefold decrease was not statistically significant when compared to the control (Table 1).

\section{Exudates from $A$. minutum disrupted membranes of Amoebophrya sp}

In Experiment 3, it was tested whether or not the loss of autofluorescence from dinospores is concomitant to the loss of membrane integrity when exposed to $A$. minutum filtrate. The most potent strain of $A$. minutum (CCMI1002) was used during this experiment. Following the exposure, a rapid decrease in the count of autofluorescent dinospores was observed, with a $40 \%$ decrease within 20 min of exposure and a $98 \%$ decrease after $2 \mathrm{~h}$ (Fig. 5a). This loss of autofluorescent dinospores was preceded by dinospore membrane permeabilization (Fig. 5b-d). After $20 \mathrm{~min}$ of exposure to the filtrate, $68 \%$ of the still autofluorescent dinospores were permeable to SytoxGreen.

\section{DISCUSSION}

Coculture experiments with $A$. minutum showed that co-occurring resistant dinoflagellates could either decrease survival of the freeliving stage of the parasite, or limit infectivity during the second generation, or both. Cells and filtrates of $A$. minutum caused similar effects to the infection dynamic, demonstrating that Dinophyceae can remotely affect parasites through the exudation of APC. Although the lytic activity of the genus Alexandrium does not seem related to bacteria [44-46], a role of dinoflagellate microbiome upon excreted APC may exist and should be explored for evidence that bacteria can modulate APC bioactivity. Once released, APC are rapidly diluted, highlighting the importance of cell density and ratios. One may expect a particularly efficient protection for cells in close contact with the APC producers. The formation of dense cell patches with concentrations orders of magnitude higher than background [47-50] is likely more protective at micro-scales as this effect is density-dependent. As effects were observed using filtrates from cultures non-exposed to Amoebophrya sp. or its chemical cues, the release of APC appears to be a passive. Despite the passive release of APC, the production of toxins and lytic compounds can induce an extra cost for Alexandrium spp. cells under certain conditions [51]. To maximize 

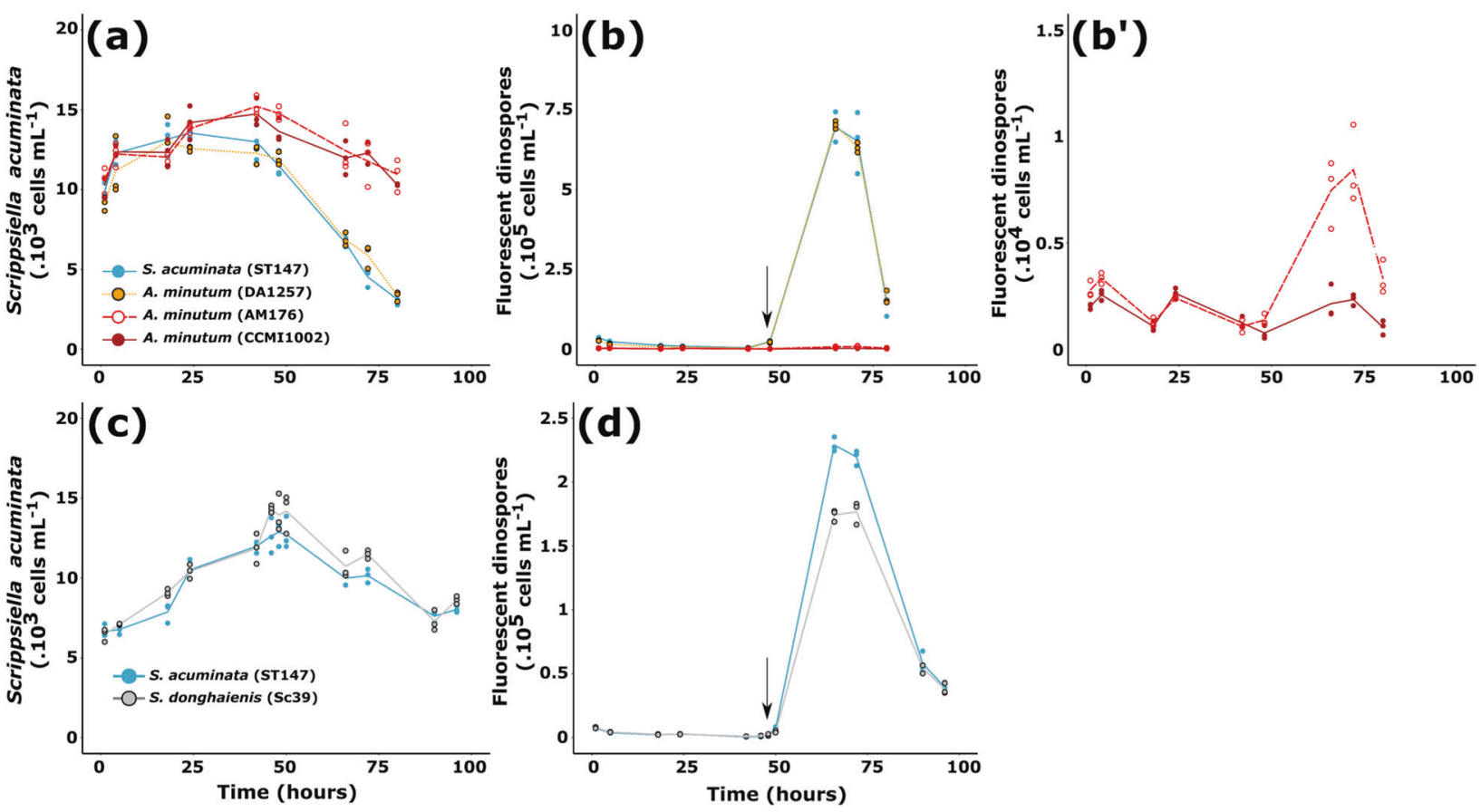

Fig. 4 Effect of filtrates on the dynamic of infection. Effect of $A$. minutum (a-b') and S. donghaienis (c, d) filtrates (Theoretical cell concentration $=10^{4}$ cells $\mathrm{mL}^{-1}$ ) on infectivity of Amoebophrya sp. dinospores on its sensitive host S. acuminata (ST147). Cell densities of S. acuminata when mixed with A25 dinospores are shown in (a, d). Dynamics of dinospores, previously exposed to the different filtrates, when mixed with the compatible host S. acuminata ST147 are shown in (b, $\mathbf{b}^{\prime}$ and $\mathbf{c}$. $\mathbf{c}$ is a zoom of (b) with dinospores densities for Am176 and CCMI1002. S. acuminata (ST147; blue), A. minutum (DA1257; yellow), A. minutum (Am176; red) and A. minutum (CCMI1002; dark red). In experiments with S. donghaienis (Sc39; gray) filtrate, the graphs show results of the experiment at a dinospore: S. acuminata ratio of 1:1; results with other ratios can be found in Supporting Information Fig. S2. The arrow represents the sampling point for prevalence analysis which results are shown in Table 1. Lines represent the mean cell densities while the symbols represent the values of each replicate $(N=3)$.

Table 1. Prevalence of Amoebophrya sp. (A25) in S. acuminata (ST147) during experiment 2 after $47 \mathrm{~h}$ of contact.

\begin{tabular}{|lcccccc|} 
& Control & CCMI1002 filtrate & p value & Control & Sc39 filtrate & $\boldsymbol{p}$ value \\
\hline Prevalence (\% of host cells) & & & & & \\
\hline Infected & $61 \pm 6$ & $35 \pm 17$ & NS & NS & $5 \pm 16$ & $44 \pm 23$ \\
\hline Early stages & $1 \pm 2$ & $16 \pm 14$ & $* * *$ & $19 \pm 7$ & $12 \pm 20$ & NS \\
\hline Advanced stages & $60 \pm 5$ & $19 \pm 4$ & $* *$ & $43 \pm 24$ & $14 \pm 3$ & NS (0.07) \\
\hline Progeny & $105 \pm 28$ & $1 \pm 0$ & NS \\
\hline
\end{tabular}

Two controls are shown as the two experiments were performed during two different sets. Results are expressed as the value or the mean \pm standard deviation. Significant values between the control and the dinophyceae treatment (CCMI1002 or Sc39) are indicated as followed: "NS" non significant, "*** 0.01 $>p$ value $>0.001, "$ "***" $p$ value $<0.001,(N=3)$.

the fitness of secondary metabolites production, Alexandrium cells can modulate lytic potency against microalgae in response to changing physicochemical conditions $[52,53]$ and toxicity in response to chemical cues from dead microalgal cells [54] or grazers [55]. Accordingly, Alexandrium cells are likely to modulate their toxin profile and quantity (including lytic compounds), in the presence of parasites. This hypothesis is further supported by the fact that $A$. fundyense can respond to waterborne cues of Amoebophrya sp. by overexpressing genes associated with defensive responses (i.e. production of reactive oxygen species) [56].

A. minutum exudates altered the integrity of the membrane prior to the loss of the natural autofluorescence of Amoebophrya sp. dinospores. The loss of cell permeability might eventually lead to an osmotic cell lysis. The release of lytic APC by A. minutum cells in the phycosphere (i.e., microenvironment surrounding the cells [57]) would act as a protective "shield" and must, at least partially, explain the resistance of $A$. minutum against Amoebophrya sp. This strategy was evidently ruled out for some Amoebophrya cells, as it has already been reported that the genus Alexandrium can be infected by Amoebophrya sp. [8,56]. This could be explained by two hypotheses: (i) either Amoebophrya sp. infects only clones of A. minutum that do not release APC or, (ii) strategies to counteract APC effects exist in Amoebophrya. The second hypothesis has already been proven with Karlodinium spp., another potential host [26]. Amoebophrya cells can acquire "antidotes" that enable them to avoid toxicity [58]. Karlodinium cells produce hydrophobic membrane permeabilizing compounds (Karlotoxins) with bioactivities, and molecular targets that are similar to the permeabilizing compounds from Alexandrium [36, 59]. The microalgal cells would be protected from their own toxins by their specific sterol membrane composition [60], a hypothesis also proposed to explain the resistance of Alexandrium cells to their own allelochemicals [59]. Cells from Amoebophrya sp. do not have a 

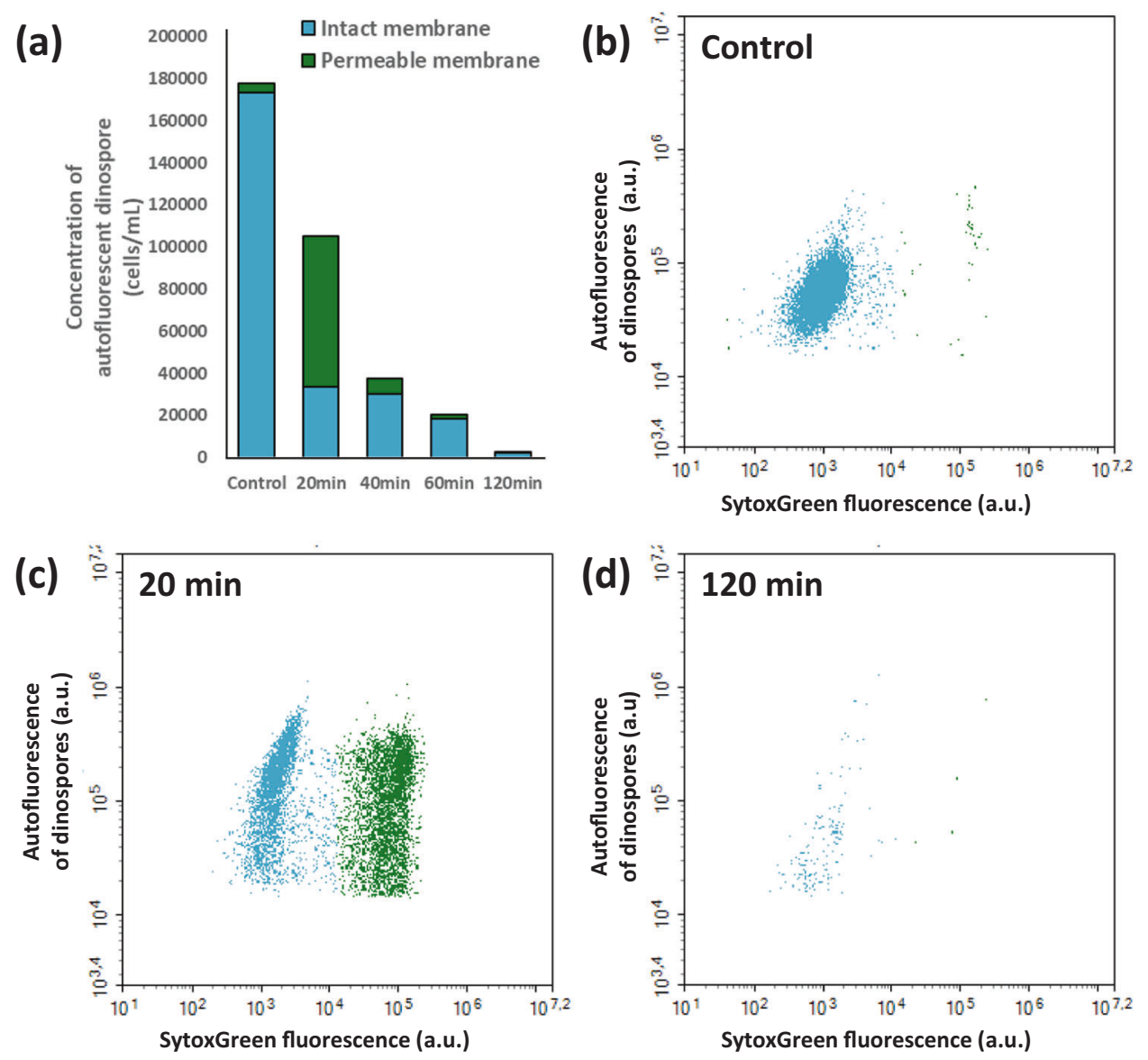

Fig. 5 Effects of $A$. minutum filtrate on the density of autofluorescent dinospores and their membrane permeability. Membrane permeability was estimated with the green fluorescence (from $488 \mathrm{~nm}$ laser) of cells with SytoxGreen, a stain that only enters cells with damaged permeable membranes. a means of the cumulative densities (cells $\mathrm{mL}^{-1}$ ) of autofluorescent dinospores with impermeable (blue) and permeable (green) membranes to the stain. $\mathbf{b}$ dinospores in the control (stained but not exposed to $A$. minutum filtrate) and exposed to $A$. minutum filtrate for c $20 \mathrm{~min}$, d $120 \mathrm{~min}$.

specific sterol signature $[27,61]$, their sterol composition is rather related to the sterols of the host. The parasite is able to retain host lipid content, including the antidote for toxins, during the infection process. This strategy enables the parasite to avoid cell lysis and to infect the host despite defense mechanisms.

Not all potential hosts are hostiles, however. The APC potency was highly variable between $A$. minutum strains and correlated with anti-microalgal [62] and ichthyotoxic $[63,64]$ activities. The mode of action of APC is similar to the mode of action of antimicroalgal allelochemicals described from the same strain [36] and from Alexandrium catenella (formerly group I of the A. tamarense/ fundyense/catenella species complex [59]). Both allelochemicals disrupt cell membranes and eventually induce cell lysis. It remains unclear whether APC are the same compounds than the ones described to have anti-microalgal or ichthyotoxic effects or distinct. Their characterization is required to answer this essential question.

Similarly, S. donghaienis passively releases APC in the surrounding environment but the potential for active defense remains to be investigated. In comparison with $A$. minutum, a different effect, probably mediated by different molecules, was observed in the presence of $S$. donghaienis. The former species did not affect the survival of the free-living stage of the parasite infecting S. acuminata, but rather decreased infectivity (ability to enter the cells) and/or progeny (ability to develop and produce the next generation of dinospores). The production of extracellular bioactive compounds was reported in S. acuminata (formerly identified as $S$. trochoidea) $[65,66]$ but never tested in
S. donghaeinis. APC may also act indirectly as a signaling system for $S$. acuminata that could, in turn, modify its resistance against Amoebophrya sp., a compelling hypothesis that requires more investigation. Importantly, these results emphasize that chemical weapons are not limited to harmful algal bloom species.

It was suggested that the presence of genotypes releasing allelochemicals could facilitate the proliferation of non-allelopathic cells and, therefore, the entire population [44, 67]. Here, it was additionally demonstrated that opportunistic (and competitive) species such as $S$. acuminata could be protected from parasitism and could benefit from a few anti-parasitic producers among $A$. minutum and $S$. donghaienis populations. The cumulative protective effect provided by resistant hosts likely contributes to the survival of a sensitive dinoflagellate species in the presence of parasites, the private good becoming a public good [68]. In cooperative associations, individuals that use common goods produced by others in the absence of feedback are called cheaters. This is the case for non-allelopathic strains of Prymnesium parvum that benefit from the exclusion of competitive diatoms by another allelopathic strain [69]. Only the cheaters that are not or weakly sensitive to APC, however, will benefit from the "cure". For some microalgal species, the APC "cure" might have strong deleterious side effects. At least, a negative effect of A. minutum cells (but not of the filtrate) was observed on the growth of S. acuminata in cocultures. After all, our results highlight a potential protective role of APC for the dinoflagellate but also suggest that the complexity of planktonic community structure in environmental communities may lead to unexpected outcomes. 
APC producers never completely eliminated the parasite, as illustrated by the production of a novel generation of dinospores even in the presence of microalgal cells with a strong APC activity. These results suggest that once inside their host, the parasites may be somewhat protected from APC. Eventually, such chemical defenses that moderate infections could contribute to the maintenance of the parasite in time, whilst avoiding the collapse of host populations. More generally, allelopathy prevents competitive exclusion and promotes biodiversity in phytoplankton by favoring weaker competitors for nutrients [67]. Similarly, APC might promote biodiversity of parasites by favoring the most resistant parasite that may not be the most virulent. Indeed, these results well explain the discrepancies between the virulence of parasites that kill $100 \%$ of host cells within few days in the laboratory (this study and others; $[23,70]$ ), and the coexistence of hosts and parasites in ecological studies that include sensitive populations [71, 72]. All of these effects contribute to the explanation of the plankton paradox [73]. Chemical interactions between microorganisms tend to promote biodiversity [67, 74]. They limit the effect of competitive exclusion for nutrients (or hosts for parasites) within the plankton community and could partially explain the coexistence of different parasitic cryptic species competing for the same host as reported by [18].

Despite the ubiquity of the genus Amoebophrya sp. in marine ecosystems, many open questions remain about regulation of the parasite dynamic. This study highlighted the release of exudates deleterious to free-life stages of Amoebophrya sp. by resistant dinoflagellates. Chemical defenses must play a role in the resistance of dinoflagellates to parasites and more largely a role in their competitiveness. The exudation of anti-parasitic metabolites by resistant hosts in the surrounding environment provides a novel mechanistic link between a host-parasite couple and the surrounding community without the need of physical contact. The exudates not only protect the producer against parasitism but also have the potential to affect the entire community by decreasing propagation of the parasite. This study revealed the importance of the plankton community composition during parasite infection as the severity of the effect fluctuated depending on the species and the strains of the resistant partner, concentrations, and/or the ratios between the different partners. Another factor that has not been assessed in this study but requires further consideration is the potential for chemosensing in these interactions. Some parasites such as the generalist parasite Parvilucifera sinerae, can "sense" infochemicals from potential hosts [75], even though they cannot actively select a compatible host [21]. Chemosensing of resistant host infochemicals by a parasite may significantly reduce the efficiency of anti-parasitic defenses and should be studied through micro-scale studies. Although "reductionist" experiments are essential to disentangle interactomes [76], -omic tools will be essential in further studies to identify the APC chemical weapons and assess physiological mode of action. Beside their ecological relevance, the use of APC extracted from dinoflagellates could be a mean to mitigate the parasites with devastating effects on algal mass cultures [77].

\section{REFERENCES}

1. Carlson CJ, Burgio KR, Dougherty ER, Phillips AJ, Bueno VM, Clements CF, et al. Parasite biodiversity faces extinction and redistribution in a changing climate. Sci Adv. 2017;3:e1602422.

2. Johnson PTJ, Preston DL, Hoverman JT, LaFonte BE. Host and parasite diversity jointly control disease risk in complex communities. Proc Natl Acad Sci USA. 2013;110:16916-21.

3. Dougherty ER, Carlson CJ, Bueno VM, Burgio KR, Cizauskas CA, Clements CF, et al. Paradigms for parasite conservation: parasite conservation. Conserv Biol. 2016;30:724-33.

4. Paseka RE, White LA, Van de Waal DB, Strauss AT, González AL, Everett RA, et al. Disease-mediated ecosystem services: pathogens, plants, and people. Trends Ecol Evolut. 2020;35:731-43.
5. Lima-Mendez G, Faust K, Henry N, Decelle J, Colin S, Carcillo F, et al. Determinants of community structure in the global plankton interactome. Science. 2015;348:1262073.

6. Bjorbækmo MFM, Evenstad A, Røsæg LL, Krabberød AK, Logares R. The planktonic protist interactome: where do we stand after a century of research? ISME J. 2020;14:544-59.

7. Brussaard CPD. Viral control of phytoplankton populations-a review. J Eukaryot Microbiol. 2004;51:125-38.

8. Chambouvet A, Morin P, Marie D, Guillou L. Control of toxic marine dinoflagellate blooms by serial parasitic killers. Science. 2008;322:1254-7.

9. Vardi A, Van Mooy BA, Fredricks HF, Popendorf KJ, Ossolinski JE, Haramaty L, et al. Viral glycosphingolipids induce lytic infection and cell death in marine phytoplankton. Science. 2009;326:861-5.

10. Guillou L, Viprey M, Chambouvet A, Welsh RM, Kirkham AR, Massana R, et al. Widespread occurrence and genetic diversity of marine parasitoids belonging to Syndiniales (Alveolata). Environ Microbiol. 2008;10:3349-65.

11. de Vargas C, Audic S, Henry N, Decelle J, Mahé F, Logares R, et al. Eukaryotic plankton diversity in the sunlit ocean. Science. 2015;348:1261605.

12. Siano R, Alves-de-Souza C, Foulon E, Bendif EM, Simon N, Guillou L, et al. Distribution and host diversity of Amoebophryidae parasites across oligotrophic waters of the Mediterranean Sea. Biogeosciences. 2011;8:267-78.

13. Park M, Cooney S, Yih W, Coats D. Effects of two strains of the parasitic dinoflagellate Amoebophrya on growth, photosynthesis, light absorption, and quantum yield of bloom-forming dinoflagellates. Mar Ecol Prog Ser. 2002;227:281-92.

14. Velo-Suárez L, Brosnahan ML, Anderson DM, McGillicuddy DJ. A Quantitative assessment of the role of the parasite Amoebophrya in the termination of Alexandrium fundyense blooms within a small coastal embayment. PLoS ONE. 2013;8:e81150.

15. Li C, Song S, Liu Y, Chen T. Occurrence of Amoebophrya spp. infection in planktonic dinoflagellates in Changjiang (Yangtze River) Estuary, China. Harmful Algae. 2014;37:117-24.

16. Choi CJ, Brosnahan ML, Sehein TR, Anderson DM, Erdner DL. Insights into the loss factors of phytoplankton blooms: the role of cell mortality in the decline of two inshore Alexandrium blooms. Limnol Oceanogr. 2017;62:1742-53.

17. Coats DW, Park MG. Parasitism of photosynthetic dinoflagellates by three strains of Amoebophrya (Dinophyta); parasite survival, infectivity, generation time, and host specificity. J Phycol. 2002;38:520-8.

18. Cai R, Kayal E, Alves-de-Souza C, Bigeard E, Corre E, Jeanthon C, et al. Cryptic species in the parasitic Amoebophrya species complex revealed by a polyphasic approach. Sci Rep. 2020;10:2531.

19. Anderson SR, Harvey EL. Temporal variability and ecological interactions of parasitic marine Syndiniales in coastal protist communities. mSphere. 2020;5: e00209-20.

20. Alves-de-Souza C, Pecqueur D, Le Floc'h E, Mas S, Roques C, Mostajir B, et al. Significance of plankton community structure and nutrient availability for the control of dinoflagellate blooms by parasites: a modeling approach. PLoS ONE. 2015;10:e0127623.

21. Alacid E, Park MG, Turon M, Petrou K, Garcés E. A game of russian roulette for a generalist dinoflagellate parasitoid: host susceptibility is the key to success. Front Microbiol. 2016;7:769.

22. Vincent F, Sheyn U, Porat Z, Schatz D, Vardi A. Visualizing active viral infection reveals diverse cell fates in synchronized algal bloom demise. Proc Natl Acad Sci USA. 2021;118:e2021586118.

23. Chambouvet A, Alves-de-Souza C, Cueff V, Marie D, Karpov S, Guillou L. Interplay between the parasite Amoebophrya sp. (Alveolata) and the cyst formation of the red tide dinoflagellate Scrippsiella trochoidea. Protist. 2011;162:637-49.

24. Pelusi A, De Luca P, Manfellotto F, Thamatrakoln K, Bidle KD, Montresor M. Virusinduced spore formation as a defense mechanism in marine diatoms. New Phytol. 2020;229:16951-2259.

25. Pouneva ID. Effect of abscisic acid and ontogenic phases of the host alga on the infection process in the pathosystem Scenedesmus acutus-Phlyctidium scenenedesmi. Acta Physiol Plant. 2006;28:395-400.

26. Bai X, Adolf JE, Bachvaroff T, Place AR, Coats DW. The interplay between host toxins and parasitism by Amoebophrya. Harmful Algae. 2007;6:670-8.

27. Place AR, Bai X, Kim S, Sengco MR, Wayne, Coats D. Dinoflagellate host-parasite sterol profiles dictate karlotoxin sensitivity. J Phycol. 2009;45:375-85.

28. Rohrlack T, Christiansen G, Kurmayer R. Putative antiparasite defensive system involving ribosomal and nonribosomal oligopeptides in Cyanobacteria of the Genus Planktothrix. Appl Environ Microbiol. 2013;79:2642-7.

29. Scholz B, Küpper F, Vyverman W, Ólafsson H, Karsten U. Chytridiomycosis of marine diatoms - the role of stress physiology and resistance in parasite-host recognition and accumulation of defense molecules. Marine Drugs. 2017;15:26.

30. Granéli E, Hansen PJ. Allelopathy in harmful algae: a mechanism to compete for resources? In: Granéli E, Turner JT, editors. Ecology of harmful algae. Springer Berlin Heidelberg; 2006. p. 189-201. 
31. Farhat S, Le P, Kayal E, Noel B, Bigeard E, Corre E, et al. Rapid protein evolution, organellar reductions, and invasive intronic elements in the marine aerobic parasite dinoflagellate Amoebophrya spp. BMC Biol. 2021;19:1.

32. Chapelle A, Le Bec C, Amzil Z, Dreanno C, Klouch KZ, Labry C, et al. Etude sur la proliferation de la micro algue Alexandrium minutum en rade de Brest (2014).

33. Chapelle A, Le Gac M, Labry C, Siano R, Quere J, Caradec F, et al. The Bay of Brest (France), a new risky site for toxic Alexandrium minutum blooms and PSP shellfish contamination. Harmful Algal News. 2015;51:4-5.

34. Klouch KZ, Schmidt S, Andrieux-Loyer F, Le Gac M, Hervio-Heath D, Qui-Minet ZN. et al. Historical records from dated sediment cores reveal the multidecadal dynamic of the toxic dinoflagellate Alexandrium minutum in the Bay of Brest (France). FEMS Microbiol Ecol. 2016;92:fiw101

35. Long M, Tallec K, Soudant P, Le Grand F, Donval A, Lambert C, et al. Allelochemicals from Alexandrium minutum induce rapid inhibition of metabolism and modify the membranes from Chaetoceros muelleri. Algal Res. 2018;35:508-18.

36. Long M, Peltekis A, González-Fernández C, Bailleul B, Hégaret H. Allelochemicals of Alexandrium minutum: kinetics of membrane disruption and photosynthesis inhibition in a co-occurring diatom. Harmful Algae. 2021;103:101997.

37. Starr RC, Zeikus JA. Utex-The culture collection of algae at the university of Texas at Austin 1993 List of cultures. J Phycol. 1993;29:1-106.

38. Keller M, Selvin R, Claus W, Guillard RRL. Media for the culture of oceanic ultraphytoplankton 1, 2. J Phycol. 1987;23:633-8.

39. Bigeard. Collect of Amoebophrya parasite (free-living stage) for genomic and transcriptomic analyses. 2019. Protocols.io.

40. Kim S, Gil Park M, Yih W, Coats DW. Infection of the bloom-forming thecate dinoflagellates Alexandrium affina and Gonyaulax spinifera by two strains of Amoebophrya (Dinophyta). J Phycol. 2004;40:815-22.

41. Kim S. Patterns in host range for two strains of Amoebophrya (Dinophyta) infecting thecate dinoflagellates: Amoebophrya spp. ex Alexandrium affine and ex Gonyaulax polygramma. J Phycol. 2006;42:1170-3.

42. Kayal E, Alves-de-Souza C, Farhat S, Velo-Suarez L, Monjol J, Szymczak J, et al. Dinoflagellate host chloroplasts and mitochondria remain functional during Amoebophrya Infection. Front Microbiol. 2020;11:600823.

43. $R$ Core Team. R: a language and environment for statistical computing. Vienna: $R$ Foundation for Statistical Computing.

44. John U, Tillmann U, Hülskötter J, Alpermann TJ, Wohlrab S, Van de Waal DB. Intraspecific facilitation by allelochemical mediated grazing protection within a toxigenic dinoflagellate population. Proc R Soc B. 2015;282:20141268.

45. Lelong A, Haberkorn $H$, Le Goïc N, Hégaret $H$, Soudant $P$. A new insight into allelopathic effects of Alexandrium minutum on photosynthesis and respiration of the diatom Chaetoceros neogracile revealed by photosynthetic-performance analysis and flow cytometry. Microb Ecol. 2011;62:919-30.

46. Tillmann U, Alpermann T, John U, Cembella A. Allelochemical interactions and short-term effects of the dinoflagellate Alexandrium on selected photoautotrophic and heterotrophic protists. Harmful Algae. 2008;7:52-64.

47. Durham WM, Stocker R. Thin phytoplankton layers: characteristics, mechanisms, and consequences. Annu Rev Mar Sci. 2012;4:177-207.

48. Breier RE, Lalescu CC, Waas D, Wilczek M, Mazza MG. Emergence of phytoplankton patchiness at small scales in mild turbulence. Proc Natl Acad Sci USA. 2018;115:12112-7.

49. Wheeler JD, Secchi E, Rusconi R, Stocker R. Not just going with the flow: the effects of fluid flow on bacteria and plankton. Annu Rev Cell Dev Biol. 2019;35:213-37.

50. Basterretxea G, Font-Muñoz JS, Tuval I. Phytoplankton orientation in a turbulent ocean: a microscale perspective. Front Mar Sci. 2020;7:185.

51. Blossom HE, Markussen B, Daugbjerg N, Krock B, Norlin A, Hansen PJ. The cost of toxicity in microalgae: direct evidence from the dinoflagellate Alexandrium. Front Microbiol. 2019;10:1065.

52. Martens H, Van de Waal DB, Brandenburg KM, Krock B, Tillmann U. Salinity effects on growth and toxin production in an Alexandrium ostenfeldii (Dinophyceae) isolate from The Netherlands. J Plankton Res. 2016;38:1302-16.

53. Long $M$, Holland $A$, Planquette $H$, González Santana $D$, Whitby $H$, Soudant $P$, et al. Effects of copper on the dinoflagellate Alexandrium minutum and its allelochemical potency. Aquat Toxicol. 2019;210:251-61.

54. Brown ER, Kubanek J. Harmful alga trades off growth and toxicity in response to cues from dead phytoplankton. Limnol Oceanogr. 2020;65:1723-33.

55. Selander E, Thor P, Toth G, Pavia H. Copepods induce paralytic shellfish toxin production in marine dinoflagellates. Proc R Soc B. 2006;273:1673-80.

56. Lu Y, Wohlrab S, Groth M, Glöckner G, Guillou L, John U. Transcriptomic profiling of Alexandrium fundyense during physical interaction with or exposure to chemical signals from the parasite Amoebophrya. Mol Ecol. 2016;25:1294-307.

57. Seymour JR, Amin SA, Raina J-B, Stocker R. Zooming in on the phycosphere: the ecological interface for phytoplankton-bacteria relationships. Nat Microbiol. 2017;2:17065.

58. Place A, Harvey $H$, Bai $X$, Coats D. Sneaking under the toxin surveillance radar: parasitism and sterol content. Afr J Mar Sci. 2006;28:347-51.
59. Ma H, Krock B, Tillmann U, Bickmeyer U, Graeve M, Cembella A. Mode of action of membrane-disruptive lytic compounds from the marine dinoflagellate Alexandrium tamarense. Toxicon. 2011;58:247-58.

60. Deeds J, Place A. Sterol-specific membrane interactions with the toxins from Karlodinium micrum (Dinophyceae) - a strategy for self-protection? Afr J Mar Sci. 2006:28:421-5.

61. Leblond JD, Sengco MR, Sickman JO, Dahmen JL, Anderson DM. Sterols of the Syndinian dinoflagellate Amoebophrya sp., a parasite of the dinoflagellate Alexandrium tamarense (Dinophyceae). J Eukaryotic Microbiol. 2006;53:211-6.

62. Long $M$, Tallec K, Soudant $P$, Lambert $C$, Le Grand F, Sarthou G, et al. A rapid quantitative fluorescence-based bioassay to study allelochemical interactions from Alexandrium minutum. Environ Pollut. 2018;242:1598-605.

63. Borcier E, Morvezen R, Boudry P, Miner P, Charrier G, Laroche J, et al. Effects of bioactive extracellular compounds and paralytic shellfish toxins produced by Alexandrium minutum on growth and behaviour of juvenile great scallops Pecten maximus. Aquatic Toxicol. 2017;184:142-54.

64. Castrec J, Soudant P, Payton L, Tran D, Miner P, Lambert C, et al. Bioactive extracellular compounds produced by the dinoflagellate Alexandrium minutum are highly detrimental for oysters. Aquat Toxicol. 2018;199:188-98.

65. Wang $\mathrm{Y}$, Tang X. Interactions between Prorocentrum donghaiense Lu and Scrippsiella trochoidea (Stein) Loeblich III under laboratory culture. Harmful Algae. 2008;7:65-75.

66. Tang YZ, Gobler CJ. Lethal effects of Northwest Atlantic Ocean isolates of the dinoflagellate, Scrippsiella trochoidea, on Eastern oyster (Crassostrea virginica) and Northern quahog (Mercenaria mercenaria) larvae. Mar Biol. 2012; 159:199-210.

67. Felpeto $A B$, Roy $S$, Vasconcelos VM. Allelopathy prevents competitive exclusion and promotes phytoplankton biodiversity. Oikos. 2018;127:85-98.

68. Driscoll WW, Hackett JD, Ferrière R. Eco-evolutionary feedbacks between private and public goods: evidence from toxic algal blooms. Ecol Lett. 2016; 19:81-97.

69. Driscoll WW, Espinosa NJ, Eldakar OT, Hackett JD. Allelopathy as an emergent, exploitable public good in the bloom-forming microalga Prymnesium parvum. Evolution. 2013;67:1582-90.

70. Rodríguez F, Figueroa Rl. Confirmation of the wide host range of Parvilucifera corolla (Alveolata, Perkinsozoa). Eur J Protistol. 2020;74:125690.

71. Chambouvet A, Laabir M, Sengco M, Vaquer A, Guillou L. Genetic diversity of Amoebophryidae (Syndiniales) during Alexandrium catenella/tamarense (Dinophyceae) blooms in the Thau lagoon (Mediterranean Sea, France). Res Microbiol. 2011;162:959-68

72. Cosgrove S. Monitoring methods and bloom dynamic studies of the toxic dinoflagellate genus Alexandrium. 2014. Doctoral dissertation, National University of Ireland, Galway.

73. Hutchinson GE. The Paradox of the plankton. Am Nat. 1961;95:137-45.

74. Czaran TL, Hoekstra RF, Pagie L. Chemical warfare between microbes promotes biodiversity. Proc Natl Acad Sci USA. 2002;99:786-90.

75. Garcés E, Alacid E, Reñé A, Petrou K, Simó R. Host-released dimethylsulphide activates the dinoflagellate parasitoid Parvilucifera sinerae. ISME J. 2013; 7:1065-8.

76. Fitzpatrick CR, Salas-González I, Conway JM, Finkel OM, Gilbert S, Russ D. et al. The plant microbiome: from ecology to reductionism and beyond. Annu Rev Microbiol. 2020;74:annurev-micro-022620-014327

77. Carney LT, Lane TW. Parasites in algae mass culture. Front Microbiol. 2014;5:278.

\section{ACKNOWLEDGEMENTS}

This study was carried out with the financial support of IFREMER, the Centre National de la Recherche Scientifique (CNRS), Sorbonne Université, the Région Bretagne and the GDR Phycotox (a CNRS/IFREMER network on HABs). It results from different projects: the project PARALLAX (IFREMER), the project PARACIDE (SAD2018 Région Bretagne/IFREMER, GDR Phycotox) and the PRC France-Korea MALV-REF. The authors would like to warmly thank Dr. Natalia Llopis Monferrer for the help with the illustrations and Prof. Dianne F. Jolley as well as Dr. Gary H. Wikfors for the constructive comments and English corrections of the manuscript. We also would like to thank Aurore Regaudie de Gioux for her constructive support during the writting of this article.

\section{AUTHOR CONTRIBUTIONS}

ML, LG, CJ, MS, and MLG designed the study. ML, JS, DM, JT, EB and CJ performed the experiments. $M L, L G$, and $C J$ performed the data analysis and wrote the manuscript that was discussed and revised by all co-authors. 
10

\section{COMPETING INTERESTS}

The authors declare no competing interests.

\section{ADDITIONAL INFORMATION}

Supplementary information The online version contains supplementary material available at https://doi.org/10.1038/s43705-021-00035-x.

Correspondence and requests for materials should be addressed to M.L.

Reprints and permission information is available at http://www.nature.com/ reprints

Publisher's note Springer Nature remains neutral with regard to jurisdictional claims in published maps and institutional affiliations.
Open Access This article is licensed under a Creative Commons Attribution 4.0 International License, which permits use, sharing, adaptation, distribution and reproduction in any medium or format, as long as you give appropriate credit to the original author(s) and the source, provide a link to the Creative Commons licence, and indicate if changes were made. The images or other third party material in this article are included in the article's Creative Commons licence, unless indicated otherwise in a credit line to the material. If material is not included in the article's Creative Commons licence and your intended use is not permitted by statutory regulation or exceeds the permitted use, you will need to obtain permission directly from the copyright holder. To view a copy of this licence, visit http://creativecommons. org/licenses/by/4.0/.

(c) The Author(s) 2021, corrected publication 2022 